\title{
Genome-wide detection of copy number variations in polled yak using the lllumina BovineHD BeadChip
}

Congjun Jia ${ }^{1,2+}$, Hongbo Wang ${ }^{1 \dagger}$, Chen $\mathrm{Li}^{1}$, Xiaoyun $\mathrm{Wu}^{1}$, Linsen Zan², Xuezhi Ding ${ }^{1}$, Xian Guo ${ }^{1}$, Pengjia Bao ${ }^{1}$, Jie Pei ${ }^{1}$, Min Chu' ${ }^{1}$, Chunnian Liang ${ }^{1 *}$ and Ping Yan ${ }^{1 *}$

\begin{abstract}
Background: Copy number variations (CNVs), which are genetic variations present throughout mammalian genomes, are a vital source of phenotypic variation that can lead to the development of unique traits. In this study we used the Illunima BovineHD BeadChip to conduct genome-wide detection of CNVs in 215 polled yaks.

Results: A total of 1066 CNV regions (CNVRs) were detected with a total length of $181.6 \mathrm{Mb}$, comprising $\sim 7.2 \%$ of the bovine autosomal genome. The size of these CNVRs ranged from $5.53 \mathrm{~kb}$ to $1148.45 \mathrm{~kb}$, with an average size of $170.31 \mathrm{~kb}$. Eight out of nine randomly chosen CNVRs were successfully validated by qPCR. A functional enrichment analysis of the CNVR-associated genes indicated their relationship to a number of molecular adaptations that enable yaks to thrive at high altitudes. One third of the detected CNVRs were mapped to QTLs associated with six classes of economically important traits, indicating that these CNVRs may play an important role in variations of these traits.

Conclusions: Our genome-wide yak CNV map may thus provide valuable insights into both the molecular mechanisms of high altitude adaptation and the potential genomic basis of economically important traits in yak.
\end{abstract}

Keywords: Polled yak, Copy number variation, Illunima BovineHD BeadChip, High altitude adaptation, Economic traits

\section{Background}

Genomic variations in terms of both sequence, as in the case of single nucleotide polymorphism base substitutions, and structure, as in instances of insertions, deletions, inversions, and copy number variations, can lead to the development of a diverse range of phenotypes that can be of economic importance when present in livestock. Copy number variations (CNVs) are a type of genome structure variation in which genomic segments ranging from $50 \mathrm{bp}$ to several $\mathrm{Mb}$ are affected by large-scale insertions, deletions, duplications, inversions, and translocations relative to the reference genome [1]. There are four primary mechanisms through which CNVs form: non-allelic homologous recombination (NAHR), non-homologous end-joining repair of double-stranded

\footnotetext{
*Correspondence: chunnian2006@163.com; pingyanlz@163.com

${ }^{\dagger}$ Congjun Jia and Hongbo Wang contributed equally to this work.

${ }^{1}$ Key Laboratory of Yak Breeding Engineering Gansu Province, Lanzhou Institute of Husbandry and Pharmaceutical Sciences, Chinese Academy of Agricultural Sciences, Lanzhou 730050, China

Full list of author information is available at the end of the article
}

breaks (NHEJ), fork stalling and template switching (FoSTeS) and retro-transposition [2, 3]. These CNVs are a major source of genetic variation [2, 4], and can cause substantial phenotypic variations through a variety of mechanisms including a gene dosage effect, changes in gene expression level, a gene blocking effect, gene fusion, a positional effect, expression of previously silent alleles, functional polymorphisms, and potential condensed effects [5]. As a common form of structural variation in vertebrate genomes, functional studies of CNVs have been conducted in many organisms. In human, $\mathrm{CNVs}$ are associated with many common diseases [6-8], including cancer [9] and autoimmunity [10]. In cattle, CNVs are correlated with parasite resistance [11], growth traits [5, 12], reproduction $[13,14]$, milk production and composition $[15,16]$, milk somatic cell scores [17], meat quality [18, 19], and feed conversion ratios [20]. In goats, CNVs in Agouti Signaling Protein $(A S I P)$ gene have identified it as a genetic factor which is associated with coat colors in different breeds [21]. In pigs, $\mathrm{CNV}$ regions harboring candidate genes 
responsible for many complex traits related to meat production and meat quality have been identified [22]. Sex-determining region Y-box 5 gene (SOX5) and SOX6 CNVs are also known to be relevant to Pea-comb and muscle development in chickens, respectively [23, 24]. CNVs in SOX6 promote the proliferation and differentiation of skeletal muscle cells as elevated SOX6 expression drives the up-regulated expression of musclegrowth-related genes in chickens [24].

The yak (Bos grunniens) lives on the Qinghai-Tibetan Plateau (QTP) - an extremely cold, harsh, and oxygen-poor ecosystem - where it serves as an essential resource for Tibetans and other nomadic peoples in this region [25]. The yak is the primary form of livestock for the inhabitants of QTP, making its economic importance clear. Despite this importance, efforts to improve the genetics of the domestic yak lag far behind those in beef cattle, dairy cattle, and other livestock. While specific genetic-based efforts made in this context are limited, as a mammal native to this highland region the yak has developed comprehensive adaptations that equip it to survive in this harsh environment $[26,27]$. As such, it is an ideal model organism to study in order to explore the formation and mechanisms of high altitude adaptation. From an evolutionary and domestication perspective, the yak also represents a unique genetic resource as it is believed to be the only large animal coexisting with its wild ancestors in a similar environment [28]. A comprehensive understanding of yak genetics thus offers an opportunity to not only accelerate genetics-based yak breeding efforts, but also to understand the molecular basis of high altitude adaptations and other unique traits in these animals.

To date only one yak CNV map is available [27], which is far less than is available for other species of livestock. Since the first three cattle CNV maps were published in 2010 [29-31], numerous additional genome-wide CNV maps have been constructed either using SNP arrays [32-34] or next-generation sequencing $[16,35,36]$. Similarly, in sheep there are now several genome-wide $\mathrm{CNV}$ maps available $[37,38]$ since the first $\mathrm{CNV}$ map publication in 2011 [39]. Given the dearth of yak CNV maps, and the fact that a significant proportion of phenotypic variation is believed to be accounted for by $\mathrm{CNVs}$ throughout mammalian genomes, there is thus a clear and urgent need to establish a comprehensive atlas of CNVs in the yak genome.

Currently, three major methods, namely array comparative genomic hybridization (CGH), SNP arrays, and next-generation sequencing (NGS), have been used to detect genome-wide CNVs in livestock, as in cattle. SNP arrays were proposed to be advantageous relative to CGH and NGS due to their lower prices, lower signal-to-noise ratios, and the use of the parameter B-allele frequency which facilitates result interpretation
[40]. In addition, SNP arrays can also provide a relatively high resolution of CNVs, although not at a level comparable to that provided by NGS, and these arrays are more convenient for high-throughput analyses and genome-wide association studies due to their quantification of allele-specific copy numbers [41]. The aforementioned yak CNV map was conducted by using an NGS-based method, and it provided valuable data for understanding yak domestication and adaptations to living in a high-altitude environment [27]. The SNP array-based method, however, has not been reported for yak genome $\mathrm{CNV}$ detection yet. Thus, considering all the advantages of these SNP arrays and the follow-up large-scale population studies including CNV-based genome-wide association studies, it is of value to evaluate CNVs throughout the yak genome using SNP arrays.

Polled yak is a new easy-to-manage breed of yak bred by scientists from the Lanzhou Institute of Husbandry and Pharmaceutical Sciences of Chinese Academy of Agricultural Sciences (CAAS) in China. In the present study, we conducted a genome-wide CNV mapping effort in yaks using SNP data from 215 polled yaks. To the best of our knowledge, this is the first yak CNVR map constructed based on Illumina BovineHD BeadChip genotype data. The objective of this study was to construct a genome-wide CNVs map of polled yaks using a SNP genotyping method in order to facilitate genetic improvements in yaks and to explore the genetic basis of high-elevation adaptation.

\section{Results}

Genome-wide detection of CNVs and CNVRs

We identified 39,388 autosomal CNVs in these 215 polled yaks, among which 37,009 CNVs were losses (deletions) and $2379 \mathrm{CNVs}$ were gains (duplications) (Additional file 1: Table S1). The ratio of loss events to gain events was $15.56: 1$. On average, each yak had 183.2 CNVs across its genome.

The size of the identified CNVs ranged from $0.697 \mathrm{~kb}$ to $4906.179 \mathrm{~kb}$, comprising 3 to 1204 SNP markers. The mean size of these CNVs was $140 \mathrm{~kb}$ and the median length was $98.745 \mathrm{~kb}$. The distribution of CNV sizes is presented in Table 1 and Fig. 1a. Almost half of the CNVs ranged from 0 to $100 \mathrm{~kb}$ in size, with $26.78 \%$ being $0-50 \mathrm{~kb}$ and $23.71 \%$ being $50-100 \mathrm{~kb}$ in length, respectively. CNVs with sizes $300-400 \mathrm{~kb}$ or larger than $400 \mathrm{~kb}$ were relatively rare.

Before merging the overlapping CNVs across all individuals to identify CNVRs, we filtered raw CNV calling results to retain only those containing $>10$ SNPs and with a size $>50 \mathrm{~kb}$. After filtering, 27,200 CNVs remained for further analysis (Additional file 2: Table S2). After merging the overlapping CNVs using the CNVRuler [42] software, 
Table 1 CNV and CNVR size distributions

\begin{tabular}{lllll}
\hline Size $(\mathrm{kb})$ & Number of CNVs & Percentage \% & $\begin{array}{l}\text { Number } \\
\text { of CNVRs }\end{array}$ & Percentage\% \\
\hline $0-50$ & 10,547 & 26.78 & 10 & 0.94 \\
$50-100$ & 9342 & 23.72 & 336 & 31.52 \\
$100-150$ & 6258 & 15.89 & 252 & 23.64 \\
$150-200$ & 4707 & 11.59 & 167 & 15.67 \\
$200-300$ & 4552 & 11.56 & 187 & 17.54 \\
$300-400$ & 1670 & 4.24 & 55 & 5.16 \\
$>400$ & 2312 & 5.87 & 59 & 5.53 \\
\hline
\end{tabular}

a total of 1066 CNVRs were obtained (Additional file 3: Table S3).

Table 1 and Fig. $1 \mathrm{~b}$ summarize the size distribution of these CNVRs. The majority of these CNVRs (31.52\%) ranged from 50 to $100 \mathrm{~kb}$ in size, while $23.64 \%$ were between 100 and $150 \mathrm{~kb}$. Overall, these CNVRs ranged from $5.53 \mathrm{~kb}$ to $1148.45 \mathrm{~kb}$, with an average size of $170.31 \mathrm{~kb}$.

Among the 1066 identified CNVRs, 55 were gain events, 959 were loss events, and 52 CNVRs were composed of both gain and loss events. Distributions of autosomal CNVRs are presented in Table 2 and Fig. 2. The total length of the identified CNVRs was $181.55 \mathrm{Mb}$, occupying $7.23 \%$ of the bovine genome (UMD_3.1). The number of CNVRs per chromosome varied from 10 on chr 18 and chr 27 to 87 on chr 1 . The percentage of CNVR as a fraction of overall chromosome length ranged from $2.56 \%$ on chr 22 to $11.91 \%$ on chr 12 .

\section{Validation of CNVRs by qPCR}

Nine CNVRs were randomly chosen to confirm the reliability of the identified CNVRs. The chosen CNVRs represented three types of $\mathrm{CNVs}$ with frequencies ranging from low to high. The results of a validation qPCR confirmed that eight of these CNVRs (88.9\%) were representative of true genomic variations (Fig. 3). The ninth was CNVR339, which was a loss-type CNV. The qPCR result for this region showed that there was no copy number loss in the samples tested, and all samples showed a copy number of two in this region.

\section{CNVRs annotation and enrichment analysis}

The BioMart tool was employed to map genes to the 1066 identified CNVRs. In total, 2111 genes overlapping with 768 CNVRs (72.05\% of the total CNVRs) were identified. These 2111 genes were classified into eight

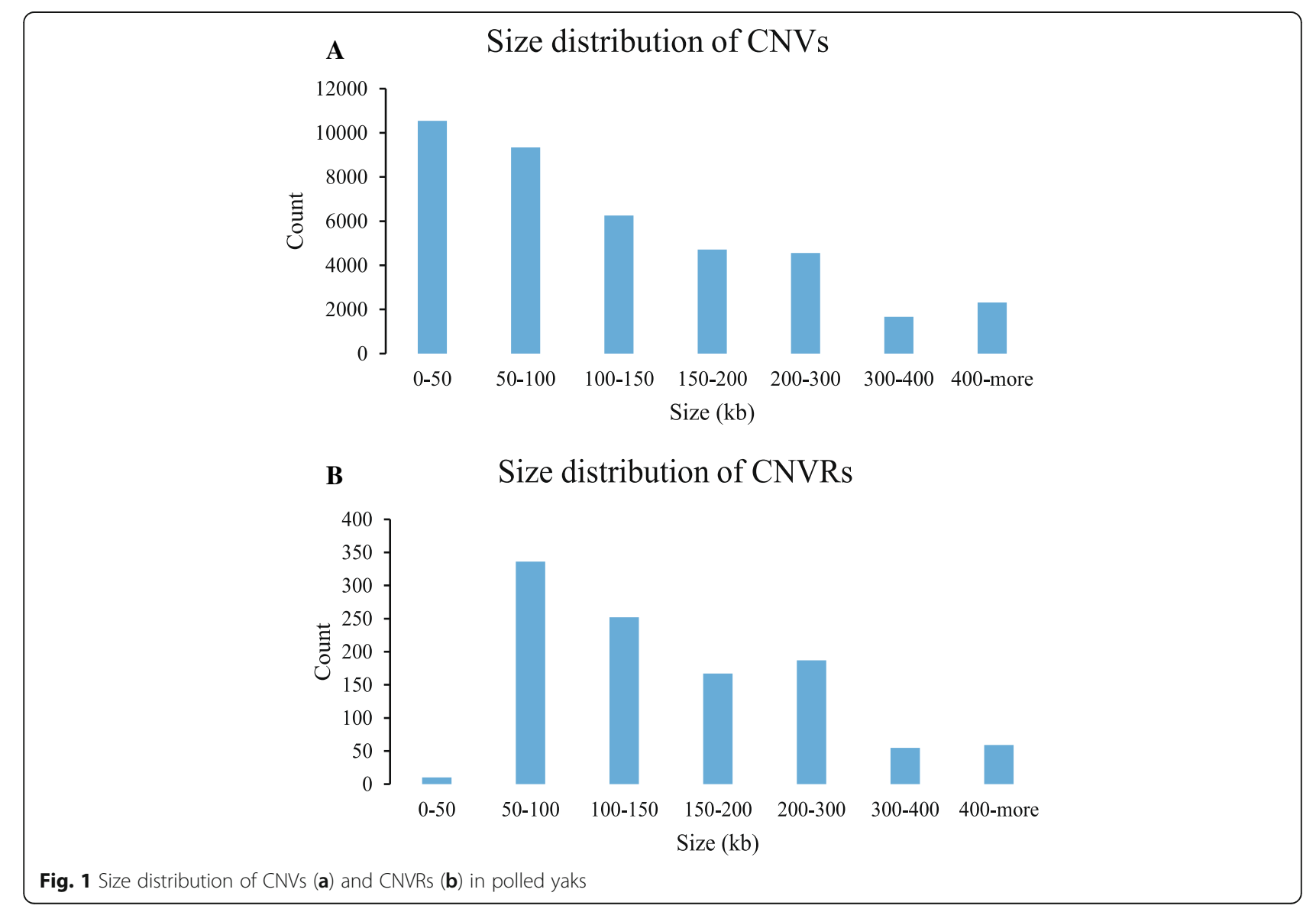


Table 2 The distribution of CNVRs in the yak genome (based

\begin{tabular}{|c|c|c|c|c|}
\hline $\mathrm{Chr}$ & $\begin{array}{l}\text { No. of } \\
\text { CNVRs }\end{array}$ & $\begin{array}{l}\text { Length of } \\
\text { CNVRs (bp) }\end{array}$ & $\begin{array}{l}\text { Length of } \\
\text { chr (bp) }\end{array}$ & $\begin{array}{l}\text { Percentage } \\
(\%)\end{array}$ \\
\hline 1 & 87 & $14,733,639$ & $158,337,067$ & 9.31 \\
\hline 2 & 57 & $11,349,756$ & $137,060,424$ & 8.28 \\
\hline 3 & 57 & $9,733,648$ & $121,430,405$ & 8.02 \\
\hline 4 & 42 & $7,735,084$ & $120,829,699$ & 6.4 \\
\hline 5 & 69 & $13,030,532$ & $121,191,424$ & 10.75 \\
\hline 6 & 57 & $9,933,389$ & $119,458,736$ & 8.32 \\
\hline 7 & 44 & $6,224,814$ & $112,638,659$ & 5.53 \\
\hline 8 & 37 & $5,417,670$ & $113,384,836$ & 4.78 \\
\hline 9 & 46 & $8,805,118$ & $105,708,250$ & 8.33 \\
\hline 10 & 41 & $7,414,048$ & $104,305,016$ & 7.11 \\
\hline 11 & 49 & $7,910,231$ & $107,310,763$ & 7.37 \\
\hline 12 & 60 & $10,854,724$ & $91,163,125$ & 11.91 \\
\hline 13 & 25 & $3,352,203$ & $84,240,350$ & 3.98 \\
\hline 14 & 43 & $8,562,586$ & $84,648,390$ & 10.12 \\
\hline 15 & 51 & $6,923,797$ & $85,296,676$ & 8.12 \\
\hline 16 & 40 & $6,421,950$ & $81,724,687$ & 7.86 \\
\hline 17 & 38 & $6,835,771$ & $75,158,596$ & 9.1 \\
\hline 18 & 10 & $2,224,179$ & $66,004,023$ & 3.37 \\
\hline 19 & 23 & $3,684,893$ & $64,057,457$ & 5.75 \\
\hline 20 & 29 & $6,019,214$ & $72,042,655$ & 8.36 \\
\hline 21 & 24 & $3,365,086$ & $71,599,096$ & 4.7 \\
\hline 22 & 12 & $1,572,517$ & $61,435,874$ & 2.56 \\
\hline 23 & 38 & $5,611,441$ & $52,530,062$ & 10.68 \\
\hline 24 & 12 & $1,668,878$ & $62,714,930$ & 2.66 \\
\hline 25 & 16 & $2,529,243$ & $42,904,170$ & 5.9 \\
\hline 26 & 18 & $3,193,189$ & $51,681,464$ & 6.18 \\
\hline 27 & 10 & $1,715,702$ & $45,407,902$ & 3.78 \\
\hline 28 & 14 & $2,331,191$ & $46,312,546$ & 5.03 \\
\hline 29 & 17 & $2,396,170$ & $51,505,224$ & 4.65 \\
\hline Total & 1066 & $181,550,663$ & $2,512,082,506$ & 7.23 \\
\hline
\end{tabular}

gene types, including 1746 protein coding genes, 54 pseudogenes, 6 processed pseudogenes, 84 miRNA genes, 13 miscRNA genes, 33 rRNA genes, 84 snoRNA genes, and 91 snRNA genes (Additional file 4: Table S4, Fig. 4b). The number of genes overlapping with gain, loss and combined gain/loss type CNVRs were 86, 1854, and 171, respectively. Since the yak population used here was comprised of 215 polled yaks, we checked the genes harbored on chr 1 . Interestingly, we found that three previously reported candidate genes for polled phenotype in yak [43] were harbored in CNVR3.

To further investigate the functions of genes harbored in these different types of CNVRs, an enrichment analysis of protein coding genes was performed independently on the three gene sets associated with gain, loss and both CNVRs (Additional file 5: Table S5). Both gene ontology annotation and Reactome pathway assessments were implemented for each enrichment analysis.

Genes overlapping with the CNV gain regions were significantly enriched in GO terms associated with lipid transport, sensory perception of chemical stimulus, sensory perception of smell, and cellular processes. A Reactome pathway analysis indicated that these genes were similarly enriched for olfactory signaling pathways, mitochondrial fatty acid beta-oxidation, metabolism of lipids, synthesis of phosphatidylcholine (PC), digestion and absorption, and FMO oxidizes nucleophiles. For gene sets composed of genes present in CNV loss regions, the GO enrichment analysis showed that these genes were primarily linked to the biological processes of nuclear transport, mitosis, and protein localization. Genes identified in the CNVRs containing both gain and loss events were linked to sensory perception of smell, fatty acid metabolism, JAK-STAT signaling, regulation of biological processes, G-protein coupled receptor signaling, and responses to stimulus. A Reactome pathway analysis of these same genes highlighted an enrichment for genes associated with the olfactory signaling pathway, the prolactin receptor signaling pathway, the growth hormone receptor signaling pathway, and the transport of fatty acids.

To estimate the potential effects of CNVRs involved in hypoxic response, the genes harbored in the identified CNVRs were queried in the hypoxia-related genes database, HypoxiaDB [44]. One hundred and sixty seven genes (11.6\% of identified named protein-coding genes) were found in the HypoxiaDB Database gene list of genes which alter their expression under hypoxic conditions (Additional file 6: Table S6). Among these, 57 genes were up-regulated under hypoxic stress, and 84 were down-regulated. For 12 of our identified genes, shifts in expression were variable depending on the degree of hypoxia, while information of the expression of the remaining 14 genes was not available.

\section{QTLs overlapping with identified CNVRs}

Three hundred and ninety six CNVRs (37.2\%) were identified to overlap with 1736 QTLs involved in six trait classes (Additional file 7: Table S7, Fig. 4c), including reproduction QTLs (31.3\%), production QTLs (13.8\%), meat and carcass QTLs (8.5\%), milk QTLs (32.8\%), exterior QTLs (7.1\%), and health QTLs (6.5\%). The number of gain, loss, and both gain/loss regions overlapping with these QTLs were 14, 368, and 14, respectively. The number of traits involved in each QTL category were 33, 29, 35, 59, 26, and 15 for QTLs associated with reproduction, production, meat and carcass, milk, exterior, and health, respectively. For production QTLs, 


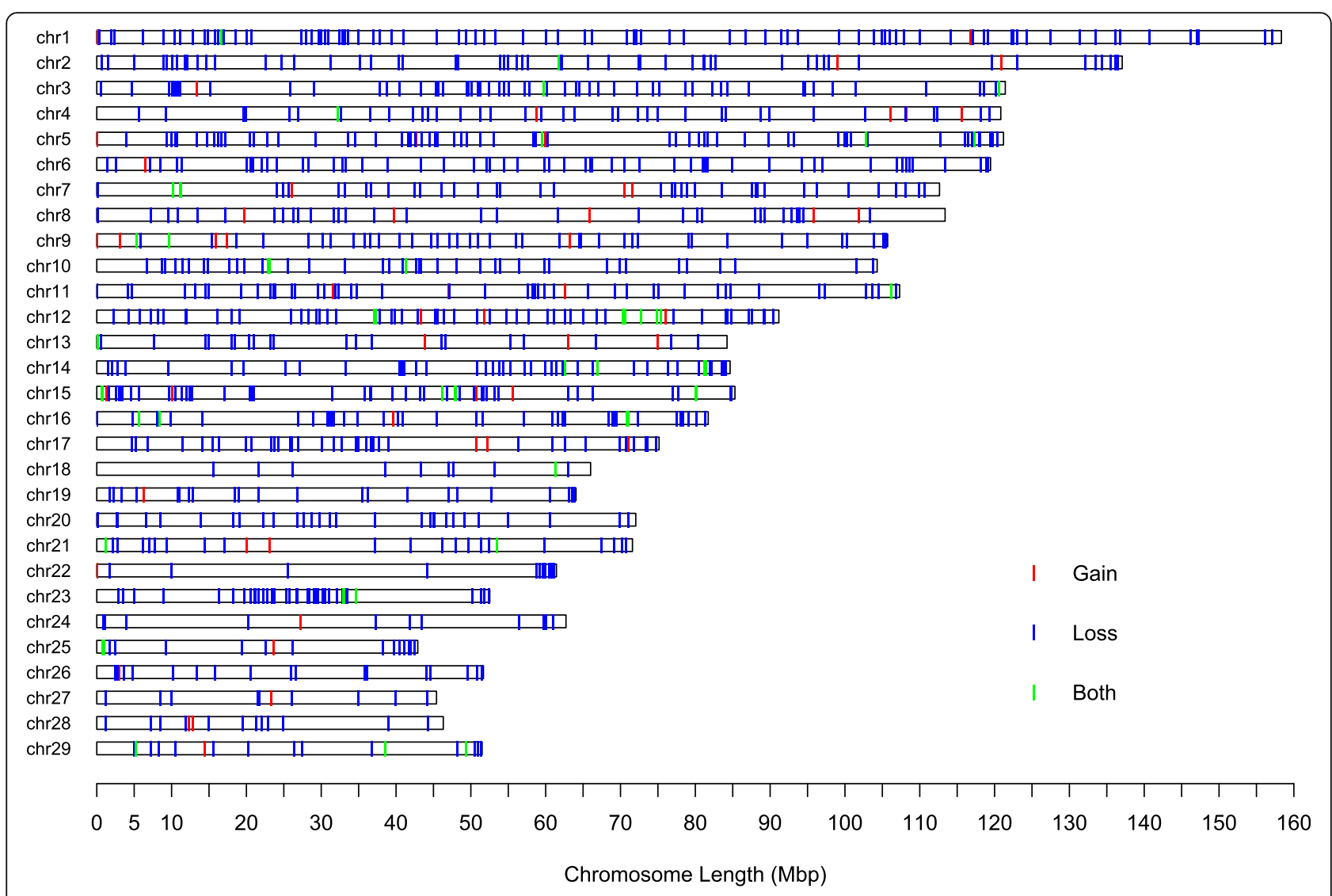

Fig. 2 Genome-wide CNVR map in polled yak. Red, blue and green represent gain events, loss events, and both gain and loss events, respectively

the majority of loci were associated with body weight across different life stages. For health-associated QTLs, the majority were associated with bovine tuberculosis susceptibility. QTLs pertaining to meat and carcass were mainly associated with lean meat yield, shear force, and longissimus muscle area.

\section{Comparison with previous studies of bovine CNVRs}

The results of a comparison of our results with 31 previously reported bovine CNVR studies are summarized in Table 3. These previous studies reported total numbers of CNVRs ranging from 19 to 4562, with lengths ranging from $4.4 \mathrm{Mb}(0.18 \%$ of the bovine genome) to $1078.5 \mathrm{Mb}$ (42.9\%). The number of CNVRs overlapping with our results ranged from 3 to 736 . The percentage of the overlapping CNVRs per study ranged from 8.0 to $48.1 \%$.

A total of 65 CNVRs were identified as being yak-specific CNVRs (Additional file 8: Table S8), after discarding the CNVRs reported by the 31 previous studies. These yak-specific or novel CNVRs included 4 gains, 59 losses, and 1 gain/loss event.

Forty-two of the 65 identified yak-specific CNVRs were annotated, containing a total of 70 genes (Additional file 9: Table S9). Functional annotation and enrichment showed that the genes harbored in these regions were significantly enriched in biological processes associated with transmembrane receptor protein tyrosine kinase signaling pathways, mesoderm development, the MAPK cascade, the regulation of molecular functions, and phosphate-containing compound metabolic processes. An additional PANTHER pathway analysis revealed that the main pathways enriched in these genes included the Ras pathway, angiogenesis, and the gonadotropin-releasing hormone receptor pathway (Additional file 10: Table S10). A total of 9 genes out of the 49 named protein coding genes in this gene set were found to be associated with hypoxic stress (Additional file 9: Table S9).

38 of the 65 yak-specific CNVRs harbored 106 QTLs associated with exterior traits, health traits, meat and carcass traits, milk traits, production traits, and reproduction traits (Additional file 11: Table S11).

\section{Discussion}

Genetic variations are vital sources of phenotypic variations associated with various traits that may be advantageous in different contexts. CNVs are a major source of genetic variation in livestock genomes, potentially affecting many economically important traits such as growth traits $[5,12,24]$, meat quality traits $[18,19,22]$, 


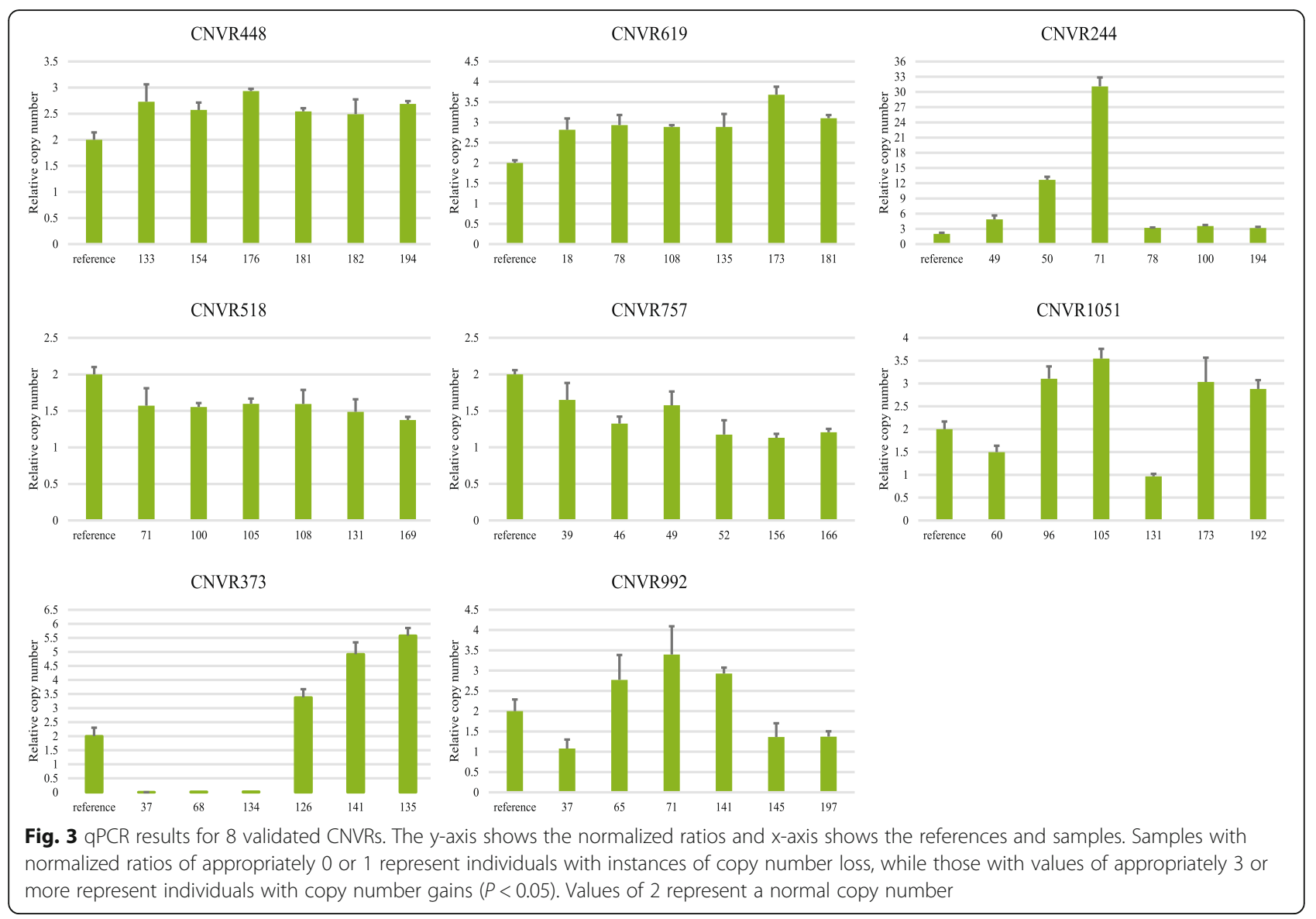

milk production [15], disease resistance [11, 63], and coat color [21]. Yaks live in an extremely harsh environment in QTP, and are well adapted to the low levels of oxygen, high levels of UV radiation, and cold temperatures endemic to this region. As such they represent an ideal organism for the study of mechanisms of high altitude adaptation. Previous studies of CNVs have revealed that $\mathrm{CNVs}$ across the genome may be linked to key environmental adaptations [64-67]. Compared to other livestock, genome-wide CNV maps for the yak genome remain limited, with just one currently being available [27].

In the present study we therefore generated the first genome-wide yak CNV map based on the Illumina BovineHD Beadchip, with the goal of assisting in yak molecular breeding and gaining new insights into the genetic architecture underlying high elevation adaptations in this species.

\section{CNVRs detected in the yak genome}

A total of 1066 CNVRs were successfully detected across the yak autosomal genome, with a total length of 181.6 $\mathrm{Mb}$, covering $\sim 7.2 \%$ of the genome. These CNVRs ranged in size from $5.53 \mathrm{~kb}$ to $1148.45 \mathrm{~kb}$, with an average size of $170.31 \mathrm{~kb}$. Eight out of the nine randomly selected
CNVRs were successfully validated by the qPCR experiment. The failure to validate the ninth CNVR may be due to inadequately designed $\mathrm{qPCR}$ primers used to confirm the CNVRs, which may have targeted an area outside of the true CNVR, because of the failure to accurately identify the real CNVR breakpoints by PennCNV [32].

In a previous report, 2634 CNVRs were discovered in the yak genome with a total length of $153 \mathrm{Mb}$, covering $\sim 5.7 \%$ of the yak genome [27]. In this previous study, the size of these CNVRs ranged from $3 \mathrm{~kb}$ to $1309 \mathrm{~kb}$ with an average size of $58 \mathrm{~kb}$.

The number of CNVRs identified in the present study is substantially lower than in the previous study. The total length and average size of the CNVRs in the present study, however, were actually larger than in the previous report. There are some reasons which may account for the differences in the CNVR results between the two studies. First of all, the CNV detection parameter of previous study was set to $>1.5 \mathrm{~kb}$, whereas in present study, only the CNVs longer than $50 \mathrm{k}$ were targeted to reduce the risk of a high false positive rate according to the user guide for the PennCNV software. This difference in filter criteria during the first step of the CNV detection may largely affect the CNVs available for CNVR definition, which may in turn have led to the 


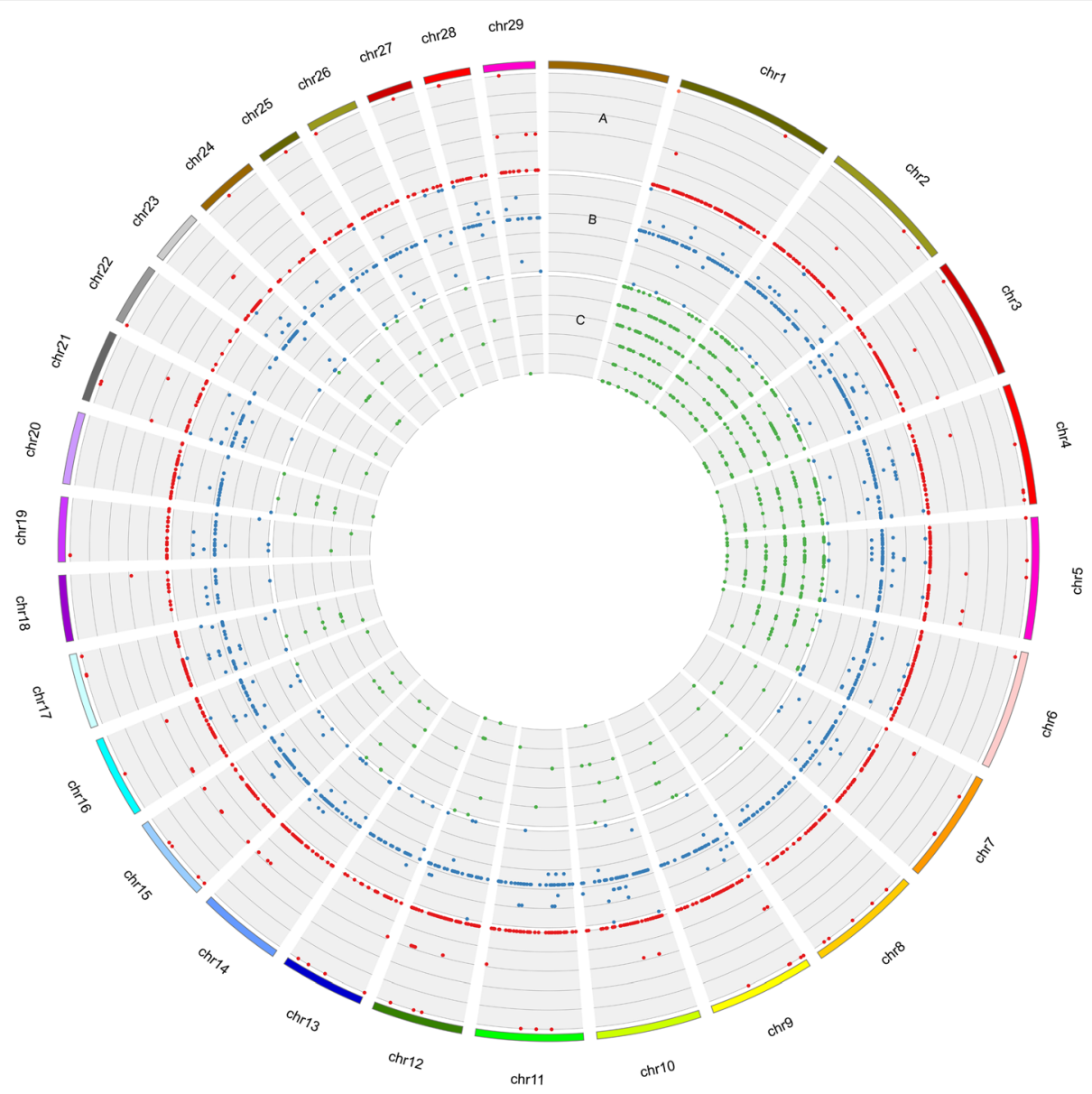

Fig. 4 Circos plot of CNVR distributions (a), harbored genes (b), and QTLS (c). Red plots on different tracks, from outside to inside, in circle A represent gain, both gain and loss, and loss events, respectively. Blue plots, from outside to inside in circle B, represent rRNA, snoRNA, snRNA, protein coding genes, pseudogenes, processed pseudogenes, miscRNA, and miRNA, respectively. Green plots in circle $C$ represent reproduction QTLs, production QTLs, milk QTLs, meat and carcass QTLs, health QTLs, and exterior QTLs, respectively

differences in both the number of CNVRs and their length. Secondly, the different platforms used for CNV calling and SNP discovery may have impacted study outcomes. Here, we generated a CNVR map based on a SNP array, while the previous study conducted resequencing to infer CNVRs. In general, CNVRs detected via SNP array are longer than those identified by resequencing as a consequence of the poorer genomic coverage of such SNP arrays $[16,41]$. Even though our present study used a high density chip-based SNP array, the coverage was less than that offered by resequencing. Thirdly, the algorithms used to detect the CNVs also differed between these two studies. In the previous report, NGS data were used for CNV detection and the CNV calling program adopted was CNVnator, which uses Read-depth (RD) analysis algorithms [68]. In the present study, the software PennCNV was employed. PennCNV is a hidden Markov model-based (HMM) algorithm that uses the $\log \mathrm{R}$ Ratio (LRR) and B Allele Frequency (BAF) in combination [69]. Fourth, the methods used to define the CNVRs were different. In this study a freely available program named CNVRuler [42] was used, while in the previous study a custom Perl script was adopted. The detailed information of parameters used for defining CNVRs of the previous study was not available. Here, we trimmed the sparse area by using the regional density (recurrence) threshold. Regions of low density of overlapping (recurrence $<0.3$ ) were not used in the analyses for a more robust definition of the beginning and end of regions. In addition, the different genetic background of the animals tested in these two studies may further contribute to this difference. A report in cattle showed that the number of CNVRs detected in a population consisting of multiple breeds may be larger than that in a population including only one breed [41]. In the present study, all samples were from one yak breed, whereas previous study tested 14 wild yaks and 65 domestic yaks from various locations across the QTP.

Given the limitations in terms of available genome-wide yak CNVR maps, we also compared our results to the 
Table 3 Comparison of our study with 31 previous bovine CNV studies conducted using various platforms

\begin{tabular}{|c|c|c|c|c|c|c|c|}
\hline Study & Platform & Breed & Sample & $\begin{array}{l}\text { CNVR } \\
\text { count }\end{array}$ & $\begin{array}{l}\text { CNVR } \\
\text { length(percentage) }\end{array}$ & $\begin{array}{l}\text { Overlapping CNVR } \\
\text { count with present study }\end{array}$ & $\begin{array}{l}\text { Overlapping } \\
\text { percentage }\end{array}$ \\
\hline Liu et al., 2010 [31] & $\mathrm{CGH}$ & 17 & 90 & 200 & $36.2 \mathrm{Mb}(1.4 \%)$ & 41 & $20.5 \%$ \\
\hline Fadista et al., $2010[30]^{*}$ & $\mathrm{CGH}$ & 4 & 20 & 224 & $9.4 \mathrm{Mb}(0.37 \%)$ & 18 & $8.0 \%$ \\
\hline Kijas et al., $2011[45]^{*}$ & $\mathrm{CGH}$ & 3 & 9 & 19 & $4.4 \mathrm{Mb}(0.18 \%)$ & 3 & $15.8 \%$ \\
\hline Zhang et al., 2014 [46]* & $\mathrm{CGH}$ & 14 & 27 & 339 & $32.8 \mathrm{Mb}(1.3 \%)$ & 46 & $13.6 \%$ \\
\hline Zhang et al., 2015a [47]* & $\mathrm{CGH}$ & 12 & 24 & 275 & $21.7 \mathrm{Mb}(0.86 \%)$ & 36 & $13.1 \%$ \\
\hline Bickhart et al., 2016 [48] & $\mathrm{CGH}$ & 8 & 75 & 1853 & $87.5 \mathrm{Mb}(3.1 \%)$ & 240 & $13.0 \%$ \\
\hline Bae et al., 2010 [29]* & $50 \mathrm{~K}$ & 1 & 265 & 359 & $62.7 \mathrm{Mb}(2.5 \%)$ & 66 & $18.4 \%$ \\
\hline Hou et al., 2011 [32] & $50 \mathrm{~K}$ & 21 & 521 & 682 & 139.8 Mb (5.5\%) & 209 & $30.6 \%$ \\
\hline Hou et al., 2012b [11 1 ${ }^{*}$ & $50 \mathrm{~K}$ & 1 & 472 & 811 & $130.0 \mathrm{Mb}(5.2 \%)$ & 185 & $22.8 \%$ \\
\hline Jiang et al., 2012 [49]* & $50 \mathrm{~K}$ & 1 & 2047 & 96 & $23.9 \mathrm{Mb}(0.95 \%)$ & 37 & $38.5 \%$ \\
\hline Wang et al., 2015 [50] & $50 \mathrm{~K}$ & 1 & 492 & 334 & $51.3 \mathrm{Mb}(2.0 \%)$ & 80 & $24.0 \%$ \\
\hline Gurgul et al., 2015 [51] & $50 \mathrm{~K}$ & 2 & 1160 & 106 & $176.6 \mathrm{Mb}(7.0 \%)$ & 51 & $48.1 \%$ \\
\hline Hou et al., 2012a [33] & BovineHD & 27 & 674 & 3438 & $146.9 \mathrm{Mb}(5.8 \%)$ & 542 & $15.8 \%$ \\
\hline Jiang et al., 2013 [41] & BovineHD & 1 & 96 & 367 & $42.7 \mathrm{Mb}(1.6 \%)$ & 94 & $25.6 \%$ \\
\hline Wu et al., 2015 [52] & BovineHD & 1 & 792 & 263 & $35.5 \mathrm{Mb}(1.4 \%)$ & 53 & $20.2 \%$ \\
\hline Zhang et al., 2015b [53] & BovineHD & 1 & 6 & 365 & $13.1 \mathrm{Mb}(0.52 \%)$ & 65 & $17.8 \%$ \\
\hline da Silva et al., 2016a [15] & BovineHD & 1 & 1509 & 4097 & 1078.5 Mb (42.9\%) & 736 & $18.0 \%$ \\
\hline da Silva et al., 2016b [18] & BovineHD & 1 & 723 & 2649 & $170.6 \mathrm{Mb}(6.8 \%)$ & 546 & $20.6 \%$ \\
\hline Sasaki et al., 2016 [54] & BovineHD & 1 & 791 & 861 & $43.7 \mathrm{Mb}(1.7 \%)$ & 189 & $22.0 \%$ \\
\hline Xu et al., 2016 [55] & BovineHD & 8 & 300 & 263 & $15.6 \mathrm{Mb}(0.62 \%)$ & 40 & $15.2 \%$ \\
\hline Zhou et al., 2016a [56] & BovineHD & 1 & 2230 & 231 & $70.4 \mathrm{Mb}(2.8 \%)$ & 57 & $24.7 \%$ \\
\hline Zhou et al., 2016b [57] & BovineHD & 1 & 1682 & 4562 & $186 \mathrm{Mb}(7.5 \%)$ & 629 & $13.8 \%$ \\
\hline Prinsen et al., 2016 [58] & BovineHD & 1 & 1410 & 563 & $57.6 \mathrm{Mb}(2.3 \%)$ & 112 & $19.9 \%$ \\
\hline Upadhyay et al., 2017 [34] & BovineHD & 38 & 149 & 923 & $61.1 \mathrm{Mb}(2.4 \%)$ & 224 & $24.3 \%$ \\
\hline Yang et al., 2017 [59] & BovineHD & 8 & 167 & 3356 & $148.0 \mathrm{Mb}(5.8 \%)$ & 574 & $17.1 \%$ \\
\hline Karimi et al., 2018 [60] & BovineHD & 1 & 90 & 221 & $36.4 \mathrm{Mb}(1.4 \%)$ & 59 & $26.7 \%$ \\
\hline Stothard et al., 2011 [35] & Resequencing & 2 & 2 & 693 & $3.8 \mathrm{Mb}(0.15 \%)$ & 78 & $11.3 \%$ \\
\hline Bickhart et al., 2012 [36]* & Resequencing & 3 & 5 & 1032 & $41.1 \mathrm{Mb}(1.6 \%)$ & 128 & $12.4 \%$ \\
\hline Ben Sassi et al., 2016 [61] & Resequencing & 1 & 10 & 823 & $45.4 \mathrm{Mb}(1.8 \%)$ & 90 & $10.9 \%$ \\
\hline Choi et al., 2016 [62] & Resequencing & 2 & 20 & 901 & $5.5 \mathrm{Mb}(0.22 \%)$ & 137 & $15.2 \%$ \\
\hline Gao et al., 2017 [16] & Resequencing & 1 & 8 & 400 & $6.9 \mathrm{Mb}(0.27 \%)$ & 36 & $9 \%$ \\
\hline Present study & BovineHD & 1 & 215 & 1066 & 181.6 Mb (7.2\%) & - & - \\
\hline
\end{tabular}

Based on the bovine genome assembly UMD_3.1, considering only autosomal CNVRs

*: CNVRs was mapped to the Btau_4.0 genome builds in the published paper

50 K-Illumina: BovineSNP50 BeadChip

BovineHD: Illumina BovineHD BeadChip

CGH: Comparative Genomic Hybridization

numerous studies involving other bovine species such as cattle, zebu, and buffalo (Table 3). We found substantial differences in identified CNVRs among these studies, likely linked with differences in breeds, sample numbers, platforms used for $\mathrm{CNV}$ detection, and $\mathrm{CNV}$ calling algorithms used in each individual study. Four primary platforms are used for bovine genome assessment: CGH array, Illumina BovineSNP50, Illumina BovineHD BeadChip, and Resequencing. In previous reports, these different approaches were used in 6, 6, 14, and 5 studies, respectively. The differences between the three primary SNP array-based platforms are primarily centered on their relative ability to detect small CNVs in the genome [52]. A previously study compared CNVRs detected using the Illumina BovineSNP50 and Illumina BovineHD platforms, determining that CNVRs identified on the basis of low density chips were longer than those based on high density chips, emphasizing the importance of genome 
coverage to CNVR length determination [41]. Apart from the platform employed, the software and underlying algorithms likely resulted in substantial variations in results among the aforementioned 31 studies. In addition to PennCNV, there are several other software packages including QuantiSNP [70] and cnvPartition (Illumina) commonly used for CNV detection. Each algorithm has its own unique strengths and weaknesses [71], and these may influence results of CNV detection efforts. In the 31 listed studies, the software used to detect CNVs across the genome included PennCNV, cnvPartition, LUMPY [72], and GADA [73].

\section{CNVR functional enrichment analyses reveal the potential molecular adaptations to high altitudes}

The gene ontology (GO) analysis of the genes harbored in the identified CNVRs showed that they were significantly enriched for functions including sensory perception of smell and chemical stimuli (GO: 0007608 and GO: 0007606), lipid metabolism (GO: 0006869, GO: 0006633 and GO: 0006631), responses to stimuli (GO: 0050896), cellular processes (GO: 0009987), G-protein coupled receptor signaling (GO: 0007186), and JAK-STAT signaling (GO: 0007259). When we mapped the CNVRsassociated genes onto the Reactome pathway, our results confirmed that these genes were involved in olfactory signaling (R-BTA-217271) and lipid metabolism (R-BTA-1483257, R-BTA-1483191, R-BTA-77289 and R-BTA-804914). Additionally, this Reactome pathway analysis showed that these CNVRs were enriched for genes participating in prolactin receptor signaling (R-BTA-1170546), growth hormone receptor signaling (R-BTA-982772), FMO oxidation of nucleophiles (R-BTA-217271), and digestion and absorption (R-BTA-8963743).

Among these analyses, the most significantly enriched pathway was the olfactory signaling pathway, and CNVs in genes within this pathway have been found in many previous reports across many species, including cattle [18, 31], yak [27], sheep [37], dog [74], pig [75], rat [76], horse [40] and human [77]. This gene family thus varies widely between mammalian species, with evidence of ongoing evolutionary changes resulting in novel genes and gene activities - changes in which CNVs are likely to play a substantial role [78]. The identified sensory perception GO categories are of great importance for allowing organisms to effectively respond to the environment, and a comparative genome study has previously revealed that gene families relating to sensory perception in yaks are substantially expanded as compared with cattle [26]. Unlike in the cattle industry, yaks are raised in pastures without any concentrated supplement being provided for nutritive purposes. Given a previous study indicating that yaks grazed late into the night during transitional and summer seasons in pastures [79], CNVs in olfactory signaling genes may allow them to better obtain food at night. Such changes in sensory perception and olfactory signaling may thus be involved in the high elevation adaptations of yaks.

Another significantly enriched functional category among our CNVRs pertained to lipid metabolism, with detectable enrichments in genes associated with lipid transport (GO: 0006869), synthesis of phosphatidylcholine (R-BTA-1483191), fatty beta-oxidation (R-BTA-77289), and fatty acid biosynthesis (GO: 0006633). Interestingly, the function of genes relating to lipid metabolism has been found to be enriched among positive selected genes in the yak [26] and ground tit genomes [80]. Positively selected genes in animals living at high elevations may thus play an important role in the adaptation to this harsh environment, where animals are faced with low oxygen, high levels of UV radiation, and cold temperatures. Creatures living in such harsh environments must be able to sustain thermogenesis in order to survive. Lipid metabolism-related functions can enable animals, including yaks, to produce enough energy under conditions of cold temperature stress [80]. One study specifically found that the $n-3$ polyunsaturated fatty acid present in phosphatidylcholine may improve the ischemic tolerance of chronically hypoxic heart tissue [81]. As we observed a functional enrichment in the pathway associated with phosphatidylcholine synthesis among genes in $\mathrm{CNV}$ gain regions, these regions may thus be specifically linked to the high altitude adaptation of yaks.

Plant resources in high altitude regions are not only limited, but are also of low quality owing to the harsh environmental conditions. Among genes in regions associated with $\mathrm{CNV}$ gain events, the digestion and absorption pathway (R-BTA-8963743) was significantly enriched, which may be related to the ability of yaks to cope with the situation of forage shortage.

We were particularly interested in the biochemical characteristics of the "FMO oxidizes nucleophiles" pathway (R-BTA-217271). Flavin-containing-monooxygenases (FMO) can catalyze the NADPH-dependent $\mathrm{N}$ - or S-oxygenation of heteroatom-containing compounds. FMO is thought to have evolved as a xenobiotic detoxification catalyst to protect mammals from lipophilic nucleophilic plant chemicals in early environments [82]. Plants grown under abiotic stress conditions, such as those grown in cold conditions, can accumulate many phenolic secondary compounds [83], which may have toxic effects in mammals. Yaks lives in QTP feeding on plants containing high phenol levels, so CNVs in genes linked with FMO nucleophile oxidation may thus be valuable in detoxifying these plant chemicals.

To better explore the molecular adaptations of yaks to high altitude conditions, we conducted a functional analysis 
of the gene sets associated with yak-specific CNVRs. A GO analysis showed that genes in these yak-specific CNVRs were significantly enriched for biological processes involved in phosphate-containing compound metabolism (GO: 0006796), MAPK signaling (GO: 0000165), regulation of molecular functions (GO: 0065009), transmembrane receptor protein tyrosine kinase signaling (GO: 0007169), and mesoderm development (GO: 0007498). When mapping the genes onto PANTHER pathways, we identified significant enrichments for the gonadotropin-releasing hormone receptor pathway (P06664), angiogenesis (P00005), and the Ras pathway (P04393) in this gene set.

The GO term "phosphate-containing compound metabolic process" (GO: 0006796) was significantly enriched among positively selected genes involved in the hypoxia response in the ground tit [80]. Among the three pathways identified in the present study, angiogenesis (P00005) is well known to be an important process involved in responding to hypoxia by increasing the oxygen supply, a function that has also been observed in other high-elevation animals $[84,85]$.

\section{QTLs harbored in yak CNVRs are associated with economically important traits}

Previous studies have reported that many CNVRs harbor QTLs associated with economically important traits in cattle $[15,18,19]$. In this study, we therefore examined the CNVRs in the cattle QTL database, identifying a total of 1736 QTLs involved in six classes of traits (Additional file 7: Table S7) within 396 CNVRs. Affected traits included those associated with reproduction QTLs, production QTLs, meat and carcass QTLs, milk QTLs, exterior QTLs, and health QTLs. In the 65 yak-specific CNVRs, 106 QTLs were mapped to 38 CNVRs.

On the QTP, yaks are an essential source of meat for high-altitude societies, making the genetic improvement of traits pertaining to meat production and quality to be of great importance in the context of yak breeding.

Of the identified QTLs pertaining to meat and carcass quality, both intramuscular fat and shear force are considered to be two major traits that are the focus of improving meat quality in the yak industry. We found IRAK3 to be one identified candidate gene in a QTL locus associated with intramuscular fat levels. In cattle, the interleukin-1 receptor-associated kinase 1 (IRAK1) gene has been found to be differentially expressed in skeletal muscle samples containing different amounts of intramuscular fat, but the underlying mechanistic link remains uncertain [86]. The IRAK3 gene, which shares substantial homology with IRAK1, may therefore also participate in yak intramuscular fat deposition, making it a viable candidate gene for future studies aimed at improving meat quality. With regard to sheer force, MUSK, NRXN1, and TBC1D4 were identified as being candidate genes in the identified QTL loci in this study. Among these, muscle-associated receptor tyrosine kinase (MUSK) plays a central role in the formation and the maintenance of the neuromuscular junctions (NMJ) - the synapses between motor neurons and skeletal muscle. It is expressed in embryonic muscle [87], and mutations in this gene can cause fetal akinesia deformations [88]. The mechanisms by which this gene affect the sheer force of meat remains unknown, making it another viable candidate gene for further investigation aimed at improving meat quality.

\section{Conclusions}

Here, we produced the first genome-wide CNV map of yak based on the Illumina BovineHD BeadChip genotype data from 215 polled yaks. A total of 1066 CNVRs were found in the yak genome, with a total length of 181.6 $\mathrm{Mb}$, comprising $~ 7.2 \%$ of the bovine autosomal genome. Functional enrichment analyses of the genes present within these CNVRs revealed a number of potential molecular adaptations that may enable yak to live in its harsh high elevation habitat. QTL detection showed that more than one third of CNVRs overlapped with QTLs associated with economically important traits in yak. The results found here may therefore provide valuable insights into the molecular mechanisms of high altitude adaptation as well as the potential genomic basis of economically important traits in yak。 .

In the future, at least two types of studies will be needed to explore the potential value of CNVs in the yak genome. First, CNV-based genome-wide association studies including more polled yaks are required to evaluate the potential effect of these CNVs on the formation of economically important traits related to growth, meat production, milk production, reproduction, and health in these yak. Identification of genetic loci responsible for disease resistance based on $\mathrm{CNV}$ can somehow benefit the yak welfare by avoiding them suffering from the disease. In addition, SNP array data from additional yak breeds as well as other bovine species such as cattle, zebu, and buffalo should be collected and used to generate a comprehensive genome-wide bovine $\mathrm{CNV}$ map, which can offer value to the investigation of population genetics based on CNVs.

\section{Methods}

\section{Sample collection and genotyping}

The 215 experimental animals were young female polled yaks born in 2017 and originating from Datong yak farm, Datong County, Xining, Qinghai province of the People's Republic of China. Blood samples were collected from all animals. Genomic DNA was extracted from these blood samples using the EasyPure Blood Genomic DNA Kit (TransGen Biotech Co., LTD, Beijing, China). 
The concentration and purity of DNA were measured using a NANODROP 2000 Spectrophotometer (Thermo Fisher Scientific Inc., Waltham, MA USA).

The Illumina BovineHD BeadChip (Illumina Inc., CA, USA) was used to genotype the animals. The Illumina BovineHD BeadChip is the most comprehensive genome-wide genotyping array available for bovine species. It contains 777,962 SNPs uniformly spanning the bovine genome with a $3.43 \mathrm{~kb}$ mean genomic coverage.

\section{Genome-wide detection of CNVs and CNVRs}

The PennCNV software [69] was utilized to identify the CNVs in the yak genome. The GenomeStudio program was used to generate the input signal intensity file containing the information needed to call CNVs, including SNP name, chromosome, position, genotype, Log R Ratio (LRR), and B Allele Frequency (BAF). The PFB file was generated by running the perl script 'compile_pfb.pl' provided by the PennCNV program based on the average BAF of each marker in the population.

After all required files were prepared, the script 'detect_cnv.pl' was used to detect the CNVs of all individuals. The '-lastchr 29' argument was used to declare that the last autosomal chromosome as being 29 (rather than 22). To eliminate the impact of genomic waves on the CNV calling procedure, the GC model file, which was generated by calculating the $1 \mathrm{Mb}$ genomic regions surrounding each marker ( $500 \mathrm{~K}$ on each side), was used as the parameter of the option '-gcmodel'. The raw CNV calls were filtered using the perl script 'filter_cnv.pl' with the filter criteria: SNP number $>10$ and $\mathrm{CNV}$ length $>50 \mathrm{k}$.

The CNVRuler software was then used to merge the overlapping CNVs identified across all the samples. There are three methods provided by CNVRuler to define the CNVRs, namely CNV region (CNVR), Reciprocal Overlap (RO), and Fragment. Here we chose the CNVR method. The value of recurrence was set to 0.3 to trim sparse areas of the overlapping regions in order to avoid overestimating the size and frequency of CNVRs.

\section{Validation of CNVRs by qPCR}

Experimental validation of identified CNVRs was performed by qPCR using a CFX96 Real-Time System. Nine CNVRs identified by CNVRluer were chosen at random based on the CNV type (loss, gain, and both gain/loss) and frequency. The primers (Additional file 12: Table S12) were designed using the Primer3 webtool (https://www.ncbi.nlm.nih.gov/tools/primer-blast) based on UMD_3.1 genome assembly. The genomic DNA samples used for SNP genotyping were then also used for
qPCR validation. The bovine basic transcription factor 3 gene (BTF3) was used as reference gene as previously reported [5]. For each CNVR, six samples with copy number variations and one normal copy sample were chosen based on the CNV detection results from the PennCNV software to validate the inferred CNVRs.

qPCR experiments were conducted using the TB Green Premix Ex Taq PCR Reagent Kit (Takara Bio). qPCR was carried out in a total volume of $20 \mu \mathrm{L}$ and the reaction conditions were as follows: $95^{\circ} \mathrm{C}$ for $3 \mathrm{~min}$, followed by $40 \mathrm{cycles}$ for $95^{\circ} \mathrm{C}$ for $10 \mathrm{~s}, 60^{\circ} \mathrm{C}$ for $10 \mathrm{~s}$ and $72{ }^{\circ} \mathrm{C}$ for $10 \mathrm{~s}$. Three replicate reactions were performed for each sample. The $2^{-\Delta \Delta \mathrm{Ct}}$ method was used to calculate the fold changes, and $2 \times 2^{-\Delta \Delta C t}$ was calculated as the copy number of the target genes in the test samples.

\section{Gene detection and functional analysis}

Genes harbored in or partially overlapping with CNVRs were retrieved from the Ensembl Genes 93 Database using BioMart (http://useast.ensembl.org/biomart/martview/c21 08f4dd2c5515aa38f7e8a4696d95c). Functional enrichment analyses of the genes overlapping with specific CNVRs were performed using tools offered by the Gene Ontology Consortium (http://www.geneontology.org/).

Named protein coding genes were queried against to the list of hypoxia-related genes from the HypoxiaDB database [44] in order to identify the genes involved in hypoxic response harbored in yak CNVRs.

\section{QTL detection within CNVRs}

To investigate the potential associations between CNVRs and economically important traits in yaks, the Animal QTL database (https://www.animalgenome.org/cgi-bin/ QTLdb/BT/index) was employed to map the Cattle QTL loci to these CNVRs.

\section{Comparison with previous studies}

To identify yak-specific CNVRs, we compared our results with those of previous studies involving many different breeds of cattle, zebu, and buffalo. As some of these previous results were mapped on the Btau_4.0 genome builds, we converted those results from Btau_4.0 to UMD 3.1 using the LiftOver tool (https:// genome.ucsc.edu/cgi-bin/hgLiftOver) on UCSC before comparison. The CNVRs on non-autosomal chromosomes or in unplaced locations were also excluded before analysis. The yak-related CNVRs in the results of the study conducted by Zhang et al. [46] were discarded prior to comparison.

Then, functional enrichment analyses and QTL detection were performed on the yak-specific CNVRs. 


\section{Additional files}

Additional file 1: Table S1. Detail information about raw CNVs calling results. (XLSX $1726 \mathrm{~kb}$ )

Additional file 2: Table S2. Detail information about CNVs after filtering. (XLSX $1227 \mathrm{~kb}$ )

Additional file 3: Table S3. Detail information of the detected CNVRs. (XLSX $59 \mathrm{~kb}$ )

Additional file 4: Table S4. Information about Ensembl genes found to be overlapped with CNVR identified in the present study. (XLSX $134 \mathrm{~kb}$ )

Additional file 5: Table S5. Significantly enriched GO terms and Reactome pathways of genes associated with the identified CNVRs. (XLSX $11 \mathrm{~kb}$ )

Additional file 6: Table S6. Hypoxia-related genes found to be overlapped with CNVRs identified in the present study. (XLSX $16 \mathrm{~kb}$ )

Additional file 7: Table S7. Information about QTLs found to be overlapped with CNVRs identified in the present study. (XLSX 104 kb)

Additional file 8: Table S8. Detail information of the yak-specific CNVRs. (XLSX $11 \mathrm{~kb}$ )

Additional file 9: Table S9. Information about Ensembl genes found to be overlapped with yak-specific CNVRs identified in the present study. (XLSX $14 \mathrm{~kb}$ )

Additional file 10: Table S10. Significantly enriched GO terms and PANTHER pathways of genes associated with the yak-specific CNVRs. (XLSX 9 kb)

Additional file 11: Table S11. Information about QTLS found to be overlapped with yak-specific CNVRs identified in the present study. (XLSX $16 \mathrm{~kb}$ )

Additional file 12: Table S12. Detail information about primers used for CNVRs validation. (XLSX $9 \mathrm{~kb}$ )

\section{Abbreviations}

BAF: B Allele Frequency; CGH: Comparative genomic hybridization; CNV: Copy number variation; CNVR: Copy number variation region; FoSTeS: Fork stalling and template switching; GO: Gene Ontology; HMM: Hidden Markov Model; LRR: Log R Ratio; NAHR: Non-allelic homologous recombination; NGS: Next-generation sequencing; NHEJ: Nonhomologous end-joining repair of double-stranded breaks; qPCR: Real-time Quantitative Polymerase Chain Reaction; QTL: Quantitative trait locus; QTP: Qinghai-Tibetan Plateau; RD: Read-depth; SNP: Single nucleotide polymorphisms

\section{Acknowledgements}

Not applicable.

\section{Funding}

This research was funded by the Agricultural Science and Technology Innovation Program (CAAS-ASTIP-2014-LIHPS-01), the National Beef Cattle Industry Technology \& System (CARS-37) and the Special fund for basic scientific research business of central public research institutes (1610322017002). The funders had no role in study design, data collection and analysis, decision to publish, or preparation of the manuscript.

\section{Availability of data and materials}

The genotypic data used and/or analyzed during the current study are available from the corresponding author on reasonable request.

\section{Authors' contributions}

CL2 and PY conceived and designed the experiments. CJ and HW analyzed the data and drafted the manuscript. CL1 and XW performed the GPCR and visualized the results. $L Z, C L 2$ and PY reviewed and edited the original manuscript. XD, XG and PB extracted the genomic DNA. JP and MC collected the blood samples. All authors read and approved the final manuscript.

\section{Ethics approval}

All of the animal experiments were approved by the Animal Ethics Committee of Lanzhou Institute of Husbandry and Pharmaceutical Sciences, Chinese Academy of Agricultural Sciences. All animal procedures were performed in strict accordance with the guidelines proposed by the China Council on Animal Care and the Ministry of Agriculture of the People's Republic of China. We obtained written permission from the owner of the yak farm to take samples.

\section{Consent for publication}

No personal data is included in the manuscript.

\section{Competing interests}

The authors declare that they have no competing interests.

\section{Publisher's Note}

Springer Nature remains neutral with regard to jurisdictional claims in published maps and institutional affiliations.

\section{Author details}

${ }^{1}$ Key Laboratory of Yak Breeding Engineering Gansu Province, Lanzhou Institute of Husbandry and Pharmaceutical Sciences, Chinese Academy of Agricultural Sciences, Lanzhou 730050, China. ${ }^{2}$ College of Animal Science and Technology, Northwest A\&F University, Yangling 712100, China.

Received: 1 February 2019 Accepted: 2 May 2019

Published online: 14 May 2019

\section{References}

1. Feuk L, Carson AR, Scherer SW. Structural variation in the human genome. Nat Rev Genet. 2006;7(2):85-97.

2. Freeman $J$, Perry GH, Feuk $L$, Redon $R$, SA MC, Altshuler DM, Aburatani $H$, Jones KW, Tyler-Smith C, Hurles ME, et al. Copy number variation: New insights in genome diversity. Genome Res. 2006;16(8):949-61.

3. Zhang F, Gu WL, Hurles ME, Lupski JR. Copy Number Variation in Human Health, Disease, and Evolution. Annu Rev Genom Hum G. 2009;10:451-81.

4. Ganguli I. Copy number a major source of variation. Scientist. 2006;20(5):66.

5. Zhang GM, Zheng L, He H, Song CC, Zhang ZJ, Cao XK, Lei CZ, Lan XY, Qi $X L$, Chen $H$, et al. Associations of GBP2 gene copy number variations with growth traits and transcriptional expression in Chinese cattle. Gene. 2018;647:101-6.

6. Pinto D, Pagnamenta AT, Klei L, Anney R, Merico D, Regan R, Conroy J, Magalhaes TR, Correia C, Abrahams BS, et al. Functional impact of global rare copy number variation in autism spectrum disorders. Nature. 2010;466(7304):368-72.

7. Bassett AS, Scherer SW. Copy Number Variation in Tourette Syndrome. Neuron. 2017:94(6):1041-3.

8. Aerts E, Geets E, Sorber L, Beckers S, Verrijken A, Massa G, Hoorenbeeck K, Verhulst SL, Van Gaal LF, Van Hul W. Evaluation of a Role for NPY and NPY2R in the Pathogenesis of Obesity by Mutation and Copy Number Variation Analysis in Obese Children and Adolescents. Ann Hum Genet. 2018;82(1):1-10

9. Diskin SJ, Hou CP, Glessner JT, Attiyeh EF, Laudenslager M, Bosse K, Cole K, Mosse YP, Wood A, Lynch JE, et al. Copy number variation at 1q21.1 associated with neuroblastoma. Nature. 2009;459(7249):987-U112.

10. Fanciulli M, Norsworthy PJ, Petretto E, Dong R, Harper L, Kamesh L, Heward $J M, S C L$ G, de Smith A, AIF B, et al. FCGR3B copy number variation is associated with susceptibility to systemic, but not organ-specific, autoimmunity. Nat Genet. 2007;39(6):721-3.

11. Hou YL, Liu GE, Bickhart DM, Matukumalli LK, Li CJ, Song JZ, Gasbarre LC, Van Tassell CP, Sonstegard TS. Genomic regions showing copy number variations associate with resistance or susceptibility to gastrointestinal nematodes in Angus cattle. Funct Integr Genomic. 2012;12(1):81-92.

12. Xu Y, Shi T, Cai HF, Zhou Y, Lan XY, Zhang CL, Lei $C Z$, Qi XL, Chen $H$. Associations of MYH3 gene copy number variations with transcriptional expression and growth traits in Chinese cattle. Gene. 2014;535(2):106-11.

13. Yue XP, Dechow C, Chang TC, JM DJ, Marshall CE, Lei CZ, Liu WS. Copy number variations of the extensively amplified $Y$-linked genes, HSFY and ZNF280BY, in cattle and their association with male reproductive traits in Holstein bulls. BMC Genomics. 2014;15. 
14. Sasaki S, Ibi T, Akiyama T, Fukushima M, Sugimoto Y. Loss of maternal ANNEXIN A10 via a 34-kb deleted-type copy number variation is associated with embryonic mortality in Japanese Black cattle. BMC Genomics. 2016;17.

15. da Silva JM, Giachetto PF, da Silva LO, Cintra LC, Paiva SR, MEB Y, Caetano AR. Genome-wide copy number variation (CNV) detection in Nelore cattle reveals highly frequent variants in genome regions harboring QTLs affecting production traits. BMC Genomics. 2016;17

16. Gao YH, Jiang JP, Yang SH, Hou YL, Liu GE, Zhang SG, Zhang Q, Sun DX. CNV discovery for milk composition traits in dairy cattle using whole genome resequencing. BMC Genomics. 2017;18.

17. Aguilar MD, SIR P, FJR L, Padilla EG, CGV P, Bagnato A, Strillacci MG. Genomewide association study for milk somatic cell score in holstein cattle using copy number variation as markers. J Anim Breed Genet. 2017;134(1):49-59.

18. da Silva VH, LCD R, Geistlinger L, Pertille F, Giachetto PF, Brassaloti RA, Morosini NS, Zimmer R, Coutinho LL. Genome-Wide Detection of CNVs and Their Association with Meat Tenderness in Nelore Cattle. PloS one. 2016;11(6).

19. de MVA L, Peripolli E, Berton MP, FLB F, Olivieri BF, Stafuzza NB, Tonussi RL, Kluska S, HLJ C, Mueller L, et al. Association study between copy number variation and beef fatty acid profile of Nellore cattle. J Appl Genet. 2018;59(2):203-23.

20. MHD S, Oliveira GA, ASM C, Freua MC, Gomes RD, SDE S, Leme PR, Fukumasu H, Carvalho ME, Ventura RV, et al. Copy number variations and genome-wide associations reveal putative genes and metabolic pathways involved with the feed conversion ratio in beef cattle. J Appl Genet. 2016:57(4):495-504

21. Fontanesi. Copy Number Variation and Missense Mutations of the Agouti Signaling Protein (ASIP) Gene in Goat Breeds with Different Coat Colors. Cytogenet Genome Res. 2009;127(1):66.

22. Chen CY, Qiao RM, Wei RX, Guo YM, Ai HS, Ma JW, Ren J, Huang LS. A comprehensive survey of copy number variation in 18 diverse pig populations and identification of candidate copy number variable genes associated with complex traits. BMC Genomics. 2012;13.

23. Wright D, Boije H, JRS M, Bed'hom B, Gourichon D, Vieaud A, Tixier-Boichard M, Rubin CJ, Imsland F, Hallbook F, et al. Copy Number Variation in Intron 1 of SOX5 Causes the Pea-comb Phenotype in Chickens. Plos Genet. 2009:5(6).

24. Lin SD, Lin XR, Zhang ZH, Jiang MY, Rao YS, Nie QH, Zhang XQ. Copy Number Variation in SOX6 Contributes to Chicken Muscle Development. Genes. 2018;9(1)

25. Wiener G, Han JL, Long RJ: The yak. $2^{\text {nd }}$ ed. Bangkok: Regional Office for Asia and the Pacific Food and Agriculture Organization of the United Nations; 2003

26. Qiu Q, Zhang G, Ma T, Qian W, Wang J, Ye Z, Cao C, Hu Q, Kim J, Larkin DM, et al. The yak genome and adaptation to life at high altitude. Nat Genet. 2012:44(8):946-9.

27. Zhang X, Wang K, Wang L, Yang Y, Ni Z, Xie X, Shao X, Han J, Wan D, Qiu Q. Genome-wide patterns of copy number variation in the Chinese yak genome. BMC Genomics. 2016;17:379

28. Wang ZF, Shen X, Liu B, Su JP, Yonezawa T, Yu Y, Guo SC, Ho SYW, Vilà C, Hasegawa M: Phylogeographical analyses of domestic and wild yaks based on mitochondrial DNA: new data and reappraisal. J Biogeogr 2010, 37(12):2332-2344.

29. Bae JS, Cheong HS, Kim LH, Namgung S, Park TJ, Chun JY, Kim JY, CFA P, Jin $\mathrm{SL}$, Shin HD. Identification of copy number variations and common deletion polymorphisms in cattle. BMC Genomics. 2010;11(1):232.

30. Fadista J, Thomsen B, Holm L-E, Bendixen C. Copy number variation in the bovine genome. BMC Genomics. 2010;11(1):284.

31. Liu GE, Hou YL, Zhu B, Cardone MF, Jiang L, Cellamare A, Mitra A, Alexander $\sqcup$, Coutinho LL, Dell' Aquila ME, et al. Analysis of copy number variations among diverse cattle breeds. Genome Res. 2010;20(5):693-703.

32. Hou YL, Liu GE, Bickhart DM, Cardone MF, Wang K, Kim ES, Matukumalli LK, Ventura M, Song JZ, PM VR, et al. Genomic characteristics of cattle copy number variations. BMC Genomics. 2011;12.

33. Hou YL, Bickhart DM, Hvinden ML, Li CJ, Song JZ, Boichard DA, Fritz S, Eggen A, DeNise S, Wiggans GR, et al. Fine mapping of copy number variations on two cattle genome assemblies using high density SNP array. BMC Genomics. 2012;13.

34. Upadhyay M, da Silva VH, Megens HJ, MHPW V, Ajmone-Marsan P, Balteanu VA, Dunner S, Garcia JF, Ginja C, Kantanen J, et al. Distribution and Functionality of Copy Number Variation across European Cattle Populations. Front Genet. 2017:8.
35. Stothard P, Choi JW, Basu U, Sumner-Thomson JM, Meng Y, Liao XP, Moore SS. Whole genome resequencing of Black Angus and Holstein cattle for SNP and CNV discovery. BMC Genomics. 2011;12.

36. Bickhart DM, Hou YL, Schroeder SG, Alkan C, Cardone MF, Matukumalli LK, Song JZ, Schnabe RD, Ventura M, Taylor JF, et al. Copy number variation of individual cattle genomes using next-generation sequencing. Genome Res. 2012;22(4):778-90

37. Liu JS, Zhang L, Xu LY, Ren HX, Lu J, Zhang XN, Zhang SF, Zhou XL, Wei CH, Zhao FP, et al. Analysis of copy number variations in the sheep genome using 50K SNP BeadChip array. BMC Genomics. 2013;14.

38. Zhu C, Fan H, Yuan Z, Hu S, Ma X, Xuan J, Wang H, Zhang L, Wei C, Zhang $Q$, et al. Genome-wide detection of CNVs in Chinese indigenous sheep with different types of tails using ovine high-density 600K SNP arrays. Sci rep. 2016;6:27822.

39. Fontanesi L, Beretti F, Martelli PL, Colombo M, Dall'Olio S, Occidente M, Portolano B, Casadio R, Matassino D, Russo V. A first comparative map of copy number variations in the sheep genome. Genomics. 2011;97(3):158-65.

40. Metzger J, Philipp U, Lopes MS, Machado AD, Felicetti M, Silvestrelli M, Distl $\mathrm{O}$. Analysis of copy number variants by three detection algorithms and their association with body size in horses. BMC Genomics. 2013;14.

41. Jiang $L$, Jiang J, Yang J, Liu $X$, Wang J, Wang $H$, Ding $X$, Liu J, Zhang Q. Genome-wide detection of copy number variations using high-density SNP genotyping platforms in Holsteins. BMC Genomics. 2013;14(1):131.

42. Kim JH, Hu HJ, Yim SH, Bae JS, Kim SY, Chung YJ: CNVRuler: a copy number variation-based case-control association analysis tool. Bioinformatics 2012, 28(13):1790-1792.

43. Liang CN, Wang LZ, Wu XY, Wang K, Ding XZ, Wang MC, Chu M, Xie XY, Qiu Q, Yan P. Genome-wide Association Study Identifies Loci for the Polled Phenotype in Yak. PloS one. 2016;11(7).

44. Khurana P, Sugadev R, Jain J, Singh SB: HypoxiaDB: a database of hypoxiaregulated proteins. Database,2013,(2013-01-01) 2013, 2013(10):bat074.

45. Kijas JW, Barendse W, Barris W, Harrison B, McCulloch R, McWilliam S, Whan $V$. Analysis of copy number variants in the cattle genome. Gene. 2011:482(1):73-7.

46. Zhang L, Jia S, Yang M, Xu Y, Li C, Sun J, Huang Y, Lan X, Lei C, Zhou Y. Detection of copy number variations and their effects in Chinese bulls. BMC Genomics. 2014;15(1):1-9.

47. Zhang LZ, Jia SG, Plath M, Huang YZ, Li CJ, Lei CZ, Zhao X, Chen H. Impact of Parental Bos taurus and Bos indicus Origins on Copy Number Variation in Traditional Chinese Cattle Breeds. Genome Biol Evol. 2015;7(8):2352-61.

48. Bickhart DM, Xu LY, Hutchison JL, Cole JB, Null DJ, Schroeder SG, Song JZ, Garcia JF, Sonstegard TS, Van Tassell CP, et al. Diversity and populationgenetic properties of copy number variations and multicopy genes in cattle. DNA Res. 2016:23(3):253-62.

49. Jiang $L$, Jiang JC, Wang JY, Ding XD, Liu JF, Zhang Q. Genome-Wide Identification of Copy Number Variations in Chinese Holstein. PloS one. 2012;7(11).

50. Wang MD, Dzama K, Hefer CA, Muchadeyi FC. Genomic population structure and prevalence of copy number variations in South African Nguni cattle. BMC Genomics. 2015;16.

51. Gurgul A, Jasielczuk I, Szmatola T, Pawlina K, Zabek T, Zukowski K, BugnoPoniewierska M. Genome-wide characteristics of copy number variation in Polish Holstein and Polish Red cattle using SNP genotyping assay. Genetica. 2015;143(2):145-55.

52. Wu Y, Fan HZ, Jing SY, Xia JW, Chen Y, Zhang LP, Gao X, Li JY, Gao HJ, Ren HY. A genome-wide scan for copy number variations using high-density single nucleotide polymorphism array in Simmental cattle. Anim Genet. 2015;46(3):289-98.

53. Zhang QW, Ma YJ, Wang XY, Zhang Y, Zhao XX. Identification of copy number variations in Qinchuan cattle using BovineHD Genotyping Beadchip array. Mol Genet Genomics. 2015;290(1):319-27.

54. Sasaki S, Watanabe T, Nishimura S, Sugimoto Y. Genome-wide identification of copy number variation using high-density single-nucleotide polymorphism array in Japanese Black cattle. BMC Genet. 2016;17.

55. Xu LY, Hou YL, Bickhart DM, Zhou Y, Hay EA, Song JZ, Sonstegard TS, Van Tassell CP, Liu GE. Population-genetic properties of differentiated copy number variations in cattle. Sci Rep. 2016;6.

56. Zhou Y, Utsunomiya YT, Xu LY, Hay EA, Bickhart DM, Alexandre PA Rosen BD, Schroeder SG, Carvalheiro R, HHD N, et al. Genome-wide CNV analysis reveals variants associated with growth traits in Bos indicus. BMC Genomics. 2016;17. 
57. Zhou Y, Utsunomiya YT, Xu LY, Hay EA, Bickhart DM, Sonstegard TS, Van Tassell CP, Garcia JF, Liu GE. Comparative analyses across cattle genders and breeds reveal the pitfalls caused by false positive and lineage-differential copy number variations. Sci Rep. 2016;6.

58. RTMM P, Strillacci MG, Schiavini F, Santus E, Rossoni A, Maurer V, Bieber A, Gredler B, Dolezal M, Bagnato A. A genome-wide scan of copy number variants using high-density SNPs in Brown Swiss dairy cattle. Livest Sci. 2016;191:153-60.

59. Yang L, Xu LY, Zhu B, Niu H, Zhang WG, Miao J, Shi XP, Zhang M, Chen Y, Zhang LP, et al. Genome-wide analysis reveals differential selection involved with copy number variation in diverse Chinese Cattle. Sci Rep. 2017;7.

60. Karimi K, Esmailizadeh A, Wu DD, Gondro C. Mapping of genome-wide copy number variations in the Iranian indigenous cattle using a dense SNP data set. Anim Prod Sci. 2018;58(7):1192-200.

61. Ben Sassi N, González-Recio Ó, de Paz-del Río R, Rodríquez-Ramilo ST, Fernández Al. Associated effects of copy number variants on economically important traits in Spanish Holstein dairy cattle. J Dairy Sci. 2016;99(8):6371-80.

62. Choi JW, Chung WH, Lim KS, Lim WJ, Choi BH, Lee SH, Kim HC, Lee SS, Cho ES, Lee KT, et al. Copy number variations in Hanwoo and Yanbian cattle genomes using the massively parallel sequencing data. Gene. 2016;589(1):36-42.

63. Liu GE, Brown T, Hebert DA, Cardone MF, Hou YL, Choudhary RK, Shaffer J, Amazu C, Connor EE, Ventura M, et al. Initial analysis of copy number variations in cattle selected for resistance or susceptibility to intestinal nematodes. Mamm Genome. 2011;22(1-2):111-21.

64. Paudel Y, Madsen O, Megens HJ, Frantz LA, Bosse M, Bastiaansen JW, Crooijmans RP, Groenen MA. Evolutionary dynamics of copy number variation in pig genomes in the context of adaptation and domestication. BMC Genomics. 2013;14(1):449.

65. Narang A, Jha P, Kumar D, Kutum R, Mondal AK, Dash D, Mukerji M, Consortium IGV. Extensive Copy Number Variations in Admixed Indian Population of African Ancestry: Potential Involvement in Adaptation. Genome Biol Evol. 2014;6(12):3171-81.

66. Wang MD, Dzama K, Rees DJG, Muchadeyi FC. Tropically adapted cattle of Africa: perspectives on potential role of copy number variations. Anim Genet. 2016;47(2):154-64

67. de Lemos MVA, Berton MP, de Camargo GMF, Peripolli E, Silva RMD, Olivieri BF, Cesar ASM, Pereira ASC, de Albuquerque LG, de Oliveira HN, et al. Copy number variation regions in Nellore cattle: Evidences of environment adaptation. Livest Sci. 2018;207:51-8.

68. Abyzov A, Urban AE, Snyder M, Gerstein M. CNVnator: an approach to discover, genotype, and characterize typical and atypical CNVs from family and population genome sequencing. Genome Res. 2011;21(6):974-84.

69. Wang K, Li MY, Hadley D, Liu R, Glessner J, Grant SFA, Hakonarson H, Bucan M. PennCNV: An integrated hidden Markov model designed for highresolution copy number variation detection in whole-genome SNP genotyping data. Genome Res. 2007;17(11):1665-74

70. Colella S, Yau C, Taylor JM, Mirza G, Butler H, Clouston P, Bassett AS, Seller A, Holmes CC, Ragoussis J. QuantiSNP: an Objective Bayes Hidden-Markov Model to detect and accurately map copy number variation using SNP genotyping data. Nucleic Acids Res. 2007;35(6):2013-25.

71. Winchester L, Yau C, Ragoussis J. Comparing CNV detection methods for SNP arrays. Brief Funct Genomic Proteomic. 2009;8(5):353-66.

72. Layer RM, Chiang C, Quinlan AR, Hall IM. LUMPY: a probabilistic framework for structural variant discovery. Genome Biol. 2014;15(6):R84.

73. Pique-Regi R, Monso-Varona J, Ortega A, Seeger RC, Triche TJ, Asgharzadeh S. Sparse representation and Bayesian detection of genome copy number alterations from microarray data. Bioinformatics. 2008;24(3):309-18.

74. Berglund J, Nevalainen EM, Molin AM, Perloski M, Andre C, Zody MC, Sharpe T, Hitte C, Lindblad-Toh K, Lohi H, et al. Novel origins of copy number variation in the dog genome. Genome Biol. 2012;13(8).

75. Paudel Y, Madsen O, Megens HJ, Frantz LAF, Bosse M, Bastiaansen JWM Crooijmans RPMA, Groenen MAM. Evolutionary dynamics of copy number variation in pig genomes in the context of adaptation and domestication. BMC Genomics. 2013;14.

76. Guryev V, Saar K, Adamovic T, Verheul M, Van Heesch SAAC, Cook S, Pravenec M, Aitman T, Jacob H, Shull JD, et al. Distribution and functional impact of DNA copy number variation in the rat. Nat Genet. 2008;40(5):538-45.

77. Waszak SM, Hasin Y, Zichner T, Olender T, Keydar I, Khen M, Stütz AM Schlattl A, Lancet D, Korbel JO. Systematic inference of copy-number genotypes from personal genome sequencing data reveals extensive olfactory receptor gene content diversity. Plos Comput Biol. 2010;6(11): e1000988.

78. Nei M, Rooney AP. Concerted and birth-and-death evolution of multigene families. Annu Rev Genet. 2005;39:121-52.

79. Ding L, Long R, Shang Z, Wang C, Yang Y, Xu S. Feeding behaviour of yaks on spring, transitional, summer and winter pasture in the alpine region of the Qinghai-Tibetan plateau. Appl Anim Behav Sci. 2008;111(3):373-90.

80. Qu Y, Zhao H, Han N, Zhou G, Song G, Gao B, Tian S, Zhang J, Zhang R, Meng $X$, et al. Ground tit genome reveals avian adaptation to living at high altitudes in the Tibetan plateau. Nat Commun. 2013:4:2071.

81. Ježová J, Nováková O, Kolář F, Tvrzická E, Neckář J, Novák F. Chronic hypoxia alters fatty acid composition of phospholipids in right and left ventricular myocardium. Mol Cell Biochem. 2002;232(1-2):49.

82. Cashman JR. Some distinctions between flavin-containing and cytochrome P450 monooxygenases. Biochem Bioph Res Co. 2005;338(1):599-604.

83. Dicko MH, Gruppen H, Barro C, Traore AS, van Berkel WJ, Voragen AG. Impact of phenolic compounds and related enzymes in sorghum varieties for resistance and susceptibility to biotic and abiotic stresses. J Chem Ecol. 2005;31(11):2671-88.

84. Ge R-L, Cai Q, Shen Y-Y, San A, Ma L, Zhang Y, Yi X, Chen Y, Yang L, Huang $Y$, et al. Draft genome sequence of the Tibetan antelope. Nat Commun. 2013:4:1858

85. Yu L, Wang G-D, Ruan J, Chen Y-B, Yang C-P, Cao X, Wu H, Liu Y-H, Du Z-L, Wang $X-P$, et al. Genomic analysis of snub-nosed monkeys (Rhinopithecus) identifies genes and processes related to high-altitude adaptation. Nat Genet. 2016:48:947.

86. Eberlein A, Kalbe C, Goldammer T, Brunner RM, Kuehn C, Weikard R. Annotation of novel transcripts putatively relevant for bovine fat metabolism. Mol Biol Rep. 2011;38(5):2975-86.

87. Valenzuela DM, Stitt TN, Distefano PS, Rojas E, Mattsson K, Compton DL, Nunez L, Park JS, Stark JL, Gies DR, et al. Receptor Tyrosine Kinase Specific for the Skeletal-Muscle Lineage - Expression in Embryonic Muscle, at the Neuromuscular-Junction, and after Injury. Neuron. 1995;15(3):573-84.

88. Tan-Sindhunata MB, Mathijssen IB, Smit M, Baas F, de Vries Jl, van der Voorn JP, Kluijt I, Hagen MA, Blom EW, Sistermans E, et al. Identification of a Dutch founder mutation in MUSK causing fetal akinesia deformation sequence. Eur J Hum Genet. 2015;23(9):1151-7.

\section{Ready to submit your research? Choose BMC and benefit from:}

- fast, convenient online submission

- thorough peer review by experienced researchers in your field

- rapid publication on acceptance

- support for research data, including large and complex data types

- gold Open Access which fosters wider collaboration and increased citations

- maximum visibility for your research: over 100M website views per year

At BMC, research is always in progress.

Learn more biomedcentral.com/submissions 